\title{
Application Practices of Recent Academic Library Appointees
}

\section{Tyler Goldberg and Kay Womack}

\begin{abstract}
Recent academic library appointees were asked to complete a two-part survey. The first part of the study, which focused on the applicants' perceptions of resume content, was published in the November 1997 issue of College \& Research Libraries. The results of part two, which queried specific application practices, suggest that large numbers of applicants will continue to waste both their time and that of those who review their applications despite helpful information available to them. Other librarians are reported as the best source for raising applicants' awareness of ways to improve their application practices.
\end{abstract}

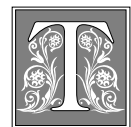

he application process and the problems frequently found in the application materials that are submitted for professional library positions have been the focus of several resources. Some authors have examined the proper construction and content of a resume or cover letter. ${ }^{1}$ In addition, many have offered suggestions for improving applications and have noted practices that waste both the applicant's time and that of potential employers. ${ }^{2}$ However, despite all this advice, applicants apply for jobs for which they do not meet the minimum qualifications and they overlook the importance of sending all materials requested in a vacancy notice. Moreover, they often submit applications after the advertised deadline and sometimes forward materials that are either unrequested or inappropriate. As the authors of this article previously noted, most guidance on proper application procedures is not based on original research but, rather, on the experience of those who have reviewed applications. ${ }^{3}$
In their survey to determine those items applicants for positions in academic libraries thought were important to include in a resume, the authors also included questions to determine some of the practices applicants followed in submitting their applications. The results of the first part of the survey, which discussed the resume content perceptions of academic library applicants new to the profession and the sources they consulted in preparing an application, have been reported previously. ${ }^{4}$ The purpose of this article is to report the findings from the second part of the survey regarding their application practices.

\section{Methodology}

One hundred recent academic library appointees listed in the "People in the News" column of the July/August 1995 through June 1996 issues of College $\mathcal{E} R e^{-}$ search Libraries News were randomly selected to receive a survey that was mailed in October 1996. Because the authors attempted to survey librarians relatively

Tyler Goldberg is Team Leader, Content Access, in the Ekstrom Library at the University of Louisville; email: stgold01@gwise.louisville.edu. Kay Womack is Head of the Reference Department in the Bizzell Library at the University of Oklahoma; e-mail: kwomack@aardvark.ou.edu. 


\begin{tabular}{|c|c|}
\hline \multicolumn{2}{|c|}{$\begin{array}{c}\text { TABLE } 1 \\
\begin{array}{c}\text { Resume Format Used } \\
(\mathbf{N}=62)\end{array} \\
\end{array}$} \\
\hline Type of Format & $\%$ \\
\hline Chronological & 34 \\
\hline Skills & 3 \\
\hline Combination & 63 \\
\hline
\end{tabular}

new to the profession, whom they defined as librarians holding professional positions for five years or less, prior to the random selection, appointees with obviously middle management or administrative titles were eliminated from consideration. After the random selection, the authors analyzed the libraries where the individuals surveyed were employed and found that each geographical region in the United States was included. In addition, private and public and small, medium, and large academic libraries were represented.

The results show that a majority of the respondents had applied for positions for which they did not meet the minimum requirements and that 21 percent submitted applications after the deadline.

As previously reported in part one of the survey, the respondents were asked to rate the relative importance of fortysix resume items. ${ }^{5}$ Questions included in part two were asked (1) to determine if the individuals surveyed met the criterion of being relatively new to the profession; (2) to learn what sources of information might influence the content of their applications; (3) to find out the type of resumes they used; (4) to elicit information about their application practices on specific issues; (5) to ascertain if faculty or academic status influenced their decisions to apply; and (6) to discover what sources they used to identify professional vacancies. The questions served two purposes: to gain insight into the survey population's application practices on certain issues, and to gather information that could be included in job application workshops the authors had conducted. The results also may suggest whether applicants pay attention to specific advice found in the literature on application preparation.

\section{Results}

Sixty-four responses were received. Because two respondents had not completed the second page of the survey, their responses were not included, giving a response rate of 62 percent on which the following analysis and discussion are based. As previously reported, the authors believe that the population surveyed met the criterion of being relatively new to the profession because 77 percent indicated that they had five years or less of experience. ${ }^{6}$

In applying for positions that request a vita or resume, an applicant usually chooses a format to follow. Having received combination as well as chronological and functional resumes, the authors were curious about the format selected by the individuals surveyed. Table 1 summarizes their responses and indicates that the majority used the combination format and very few used the skills or functional format.

Table 2 summarizes the respondents' answers to the following four questions:

- Have you ever applied for a position when you knew you did not meet the minimum required qualifications?

- Have you sent applications that did not include all materials requested in the advertisement?

- Have you submitted applications that would arrive after the application deadline?

- Have you sent materials such as transcripts or placement files when they were not requested?

The results show that a majority of the respondents had applied for positions for which they did not meet the minimum requirements and that 21 percent submitted applications after the deadline. Most applicants, however, neither sent incomplete applications nor had unrequested materials forwarded. 


\begin{tabular}{|c|c|c|}
\hline \multicolumn{3}{|c|}{$\begin{array}{c}\text { TABLE } 2 \\
\text { Selected Application Practices } \\
(\mathbf{N}=62)\end{array}$} \\
\hline \multirow[b]{2}{*}{ Practice } & \multicolumn{2}{|c|}{ Responses $(\%)$} \\
\hline & Yes & No \\
\hline $\begin{array}{l}\text { Applied knowing did not meet minimum } \\
\text { qualifications }\end{array}$ & 52 & 48 \\
\hline $\begin{array}{l}\text { Sent application without all requested } \\
\text { materials }\end{array}$ & 10 & 90 \\
\hline Submitted application after deadline & 21 & 79 \\
\hline Sent materials that were not requested & 3 & 97 \\
\hline
\end{tabular}

library applicants use the skills or functional format.

Some errors made in application practices have more significant consequences than others, which may simply be a misuse of applicants' time or may annoy members of a search committee. For example, of the application practices reported in table 2 , applying for positions for which one cannot meet the

In addition to the questions summarized in table 2 , the survey population was asked if they had ever called a library to obtain more information about an advertised opening prior to submitting an application and if faculty or academic status influenced their decision to apply. Forty-two percent reported that they had called a library before applying. Faculty or academic status did make a difference in the decision to apply for 34 percent of the respondents but did not make a difference to 66 percent.

A list of sources that can be used to advertise professional library openings was provided, and respondents were asked to check those they had used. Their responses are reported in table 3 .

\section{Discussion}

Although Jane F. Spivack has indicated that there are "basically two types of resumes," which are the chronological and functional styles, Barbara I. Dewey has noted that "a variety of successful [resume] formats can be used" when applying for professional library positions. ${ }^{7}$ However, Rosanna O'Neil, Clark C. Wong, and Robert F. Delzell have suggested that the chronological resume format is the one most often used or most preferred..$^{8}$ This position is not supported in table 1 , which reports that approximately one-third of the respondents used the chronological format and almost two-thirds used a combination format. In addition, this study indicates that very few academic postmarking an application after the advertised deadline, or failing to include all application materials requested in a vacancy notice may automatically eliminate an applicant. Sending unrequested materials may not remove one's application from serious examination, but it is unnecessary and is likely to irritate those who review the applications received for a specific opening because it wastes their time.

It is not surprising that a majority (52\%) of the respondents had applied for positions for which they did not meet the

\begin{tabular}{|c|c|c|}
\hline \multicolumn{3}{|c|}{$\begin{array}{c}\text { TABLE } 3 \\
\text { Sources Used to Identify Professional } \\
\text { Library Openings } \\
(\mathbf{N}=62)\end{array}$} \\
\hline \multirow[b]{2}{*}{ Source } & \multicolumn{2}{|c|}{ Response: } \\
\hline & $\mathrm{N}$ & $\%$ \\
\hline Professional/scholarly journals & 60 & 97 \\
\hline Job hotlines & 27 & 44 \\
\hline National & 18 & 29 \\
\hline State & 20 & 32 \\
\hline Local & 12 & 19 \\
\hline $\begin{array}{l}\text { Library school/professional } \\
\text { placement services }\end{array}$ & 33 & 53 \\
\hline Newspapers & 24 & 39 \\
\hline National & 14 & 23 \\
\hline Local & 21 & 34 \\
\hline Electronic bulletin boards/listservs & 54 & 87 \\
\hline Internet job sites & 29 & 47 \\
\hline Internal postings & 28 & 45 \\
\hline Employment agencies & 3 & 5 \\
\hline
\end{tabular}


minimum qualifications. Kay Womack reported in the three library searches she reviewed that less than 40 percent of the applicants met the minimum requirements, with the number dropping to as low as 22 percent in one search. ${ }^{9}$ Although many sources note that candidates who do not meet minimum requirements cannot be hired ${ }^{10}$ and admonish unqualified applicants not to apply so as not to waste everyone's time, ${ }^{11}$ these survey results show that many applicants still may hope that minimum qualifications will be overlooked. Qualifications are considered carefully when writing the ad, and minimum requirements cannot be waived after they are advertised, unless the search is reopened as Terrence Mech has noted. He has said: "Legally a candidate who does not meet the minimum requirements cannot be hired without reopening the search with a new set of minimum requirements. A candidate who exceeds the minimum requirements can always be hired."12 Those applicants who are unable to meet the minimum requisites should not apply as advised by Suzanne T. Larsen and Joan S. McConkey, who have said: "If you do not have the skills, education, or experience identified as requirements for the position, do not apply."13

Applicants who submit applications after the deadline, as 21 percent of the respondents in the current study indicated they had done, often are rejected from consideration automatically. In describing her experience, Womack has said that "academic libraries which use an application deadline in the vacancy notice, review only those applications postmarked on or before the deadline." ${ }^{14}$ It is important that applicants learn to recognize the difference between a deadline date and a review date. Mech has reported that a review date indicates when applications are expected but allows some legal flexibility if promising ones arrive late. ${ }^{15}$

The majority of respondents (90\%) said that they did not send an application without all materials requested in an advertisement. Although only 10 percent of the respondents reported that they had submitted incomplete applications, these individuals are likely to be eliminated early in the review process as Carole McIver and Mech have reported. ${ }^{16}$ Tyler Goldberg and Kay Womack have noted that submitting an incomplete application suggests one is disorganized or careless and does not create a favorable first impression. ${ }^{17}$ McIver and Dewey have indicated that the materials requested in the advertisement are essential, they are not negotiable, and applicants should send exactly those items. ${ }^{18}$

Sometimes applicants include material with an application that is not requested or have placement files, transcripts, and references forwarded before these items are requested. The vast majority $(97 \%)$ of the respondents in this study indicated that they had not sent transcripts or placement files when they were not requested. Although submitting unrequested materials may not be as likely to cause the three percent who had done this to automatically be removed from consideration as the other practices reported in table 2, this action may not strengthen their applications. Not only does this waste the time of the applicant, the person forwarding the material, and those reviewing the application, sometimes there is information in the placement file that is detrimental to one's candidacy. Placement files often contain letters of reference that, as Lois N. Upham has said, "may be of limited value, becoming dated rapidly" and that "may actually be harmful to the job candidates." ${ }^{19}$ As the authors have previously noted, when sending an application, "Applicants should submit placement files only if they are requested in the advertisement." 20

Applicants who take the initiative of calling a library to clarify specific issues before applying, as did 42 percent of the respondents, are commended for this action. For example, an applicant may want to be sure he or she clearly understands the job responsibilities and may want to ask for a detailed position description, as Delzell and Stuart Hannabus have suggested, before applying. ${ }^{21}$ It is beneficial 
to find out if applications are still being accepted before applying long after the advertised review date or when a vacancy notice indicates the position will be open until filled. In the case of an individual who will not receive a required ALA-accredited master of library science or equivalent degree until after the application deadline or review date listed in the job advertisement, it is prudent to ask if one's application will be considered if it is submitted. It may be helpful for both the applicant and those conducting the search to clarify points such as those illustrated above to avoid wasting everyone's time.

In the 1990s, faculty status for librarians has been threatened at a number of academic institutions, including the ones where the authors of this article are employed. Thus, the authors were interested in finding out if faculty or academic status influenced individuals' decisions in selecting positions for which to apply. The results indicated that it did make a difference for approximately one-third of the respondents, but it did not influence almost two-thirds. According to Dewey, a variety of issues have a role in the impact that rank and status play on a library's ability to recruit a specific candidate. Among these factors are the candidate's expectations and how well the local definition of rank and status compares with similar organizations. ${ }^{22}$

The question on status elicited some interesting comments. Those who answered yes viewed faculty status in both positive and negative ways. Some indicated a preference for faculty status for reasons relating to tenure and status. One respondent felt that academic or faculty status "further validates the perception across campus of librarians as professional colleagues." However, several respondents would choose not to apply, especially because of the requirements of tenure. As one noted, "Tenure places extra burdens on overworked librarians and fosters a competitive work environment; I prefer not to have it." Several respondents noted that several factors, includ-

ing faculty status, would be considerations for accepting a job. Applying only showed interest, but factors that would be considered in accepting a job would include salary, duties, geographic location, local environment, challenges and opportunities for growth, and type of status.

\section{It may be helpful for both the applicant and those conducting the search to clarify points such as those illustrated above to avoid wasting everyone's time.}

The sources that respondents relied on the most to identify professional vacancies are not completely unexpected. It is interesting to note that professional and scholarly journals continue to be the source that most used, with electronic bulletin boards/listservs a close second. Because those completing the survey are new to the field, it is not totally surprising that library school or professional placement services were used by more than 50 percent. The number that used internal postings is somewhat unexpected. In addition to the results seen in table 3, other sources given were library school newsletters, networking, word of mouth, friends/librarians, cold calling, and ALA and ACRL conferences. Specific sources mentioned were The Chronicle of Higher Education, the library hotline, and the University of Illinois job database.

A number of authors have offered advice on advertising sources. Some have directed their discussions to the job seeker. ${ }^{23}$ Elizabeth A. Lorenzen specifically has provided information for those interested in using the Internet in a job search. ${ }^{24}$ Others have focused on the employer's needs in their reviews of advertising sources. ${ }^{25}$ Knowing what sources applicants check the most to find professional library openings is beneficial not only to other applicants, but also to employers who want to use their funds wisely in advertising their vacancies to meet equal opportunity and affirmative action requirements, and to attract wellqualified candidates. Combining the re- 
sponses on the use of bulletin boards, listservs, and Internet job sites indicates that electronic sources are an important means of advertising and identifying vacancies, in addition to professional and scholarly journals and library school and professional placement services.

\section{Conclusion}

Because this discussion reported on the survey responses of librarians relatively new to the profession, the authors do not know if the results would be similar for librarians who have been employed in academic libraries for a longer period of time. However, it is encouraging to learn that very few applicants forward unrequested application materials such as transcripts or placement files and that a large number of applicants realize the value of contacting libraries to clarify questions about an opening before applying. This study indicates that faculty or academic status does not influence the decision of most applicants when choosing to apply for a position.

The results point out that of those unqualified librarians who applied for positions, more than 50 percent knew they did not meet minimum requirements. In addition, approximately 20 percent may have failed to qualify for some positions simply because they did not meet advertised deadlines and 10 percent may have been eliminated automatically at times because they did not submit all requested application materials. These findings suggest that large numbers of applicants will continue to follow some application practices that will waste both their time and that of those who receive and review their applications, regardless of attempts to raise their awareness through advice given in professional publications, on listservs, and at workshops. Although all these resources have been consulted by the respondents, as the authors previously reported, the majority of applicants consult other librarians when they want assistance in applying for library positions and preparing application materials. ${ }^{26}$ Thus, professional colleagues who have an opportunity to work with applicants on an individual basis have the best chance of helping them to maximize their prospects for interviews and, ultimately, for receiving job offers as professional librarians in academic libraries.

\section{Notes}

1. Kay Womack and Tyler Goldberg, "Resume Content: Applicants' Perceptions," College $\mathcal{E}$ Research Libraries 58 (Nov. 1997): 540-549; Philip C. Howze, "10 Job Hunting Tips for New Librarians," CERL News 58 (July/Aug. 1997): 490-491; Suzanne T. Larsen and Joan S. McConkey, "Applying for Professional Positions," CERL News 56 (June 1995): 415-417; Carol MacAdam, "Job Hunter's Workshop: How to Find and Land the Right Job and Survive the Transition," Serials Librarian 25, nos. 3-4 (1995): 358-359; Rita Broadway, "Job Descriptions vis-à-vis Applications: A Match Often Not Made in Heaven," Serials Librarian 21, nos. 2-3 (1991): 199-200; Tyler Goldberg and Kay Womack, "Academic Applicants: Make A Good First Impression," CERL News 51 (Sept. 1990): 702-704; Clark C. Wong, "Job Search: Strategies to Improve Your Success Rate," Ohio Media Spectrum 40 (spring 1988): 40-41; Barbara I. Dewey, "Writing and Analyzing Resumes and Cover Letters," in Barbara I. Dewey, Library Jobs: How to Fill Them, How to Find Them (Phoenix, Ariz: Oryx Pr., 1987), 62-73; Robert F. Delzell, Finding a Position: Strategies for Library School Graduates (Occasional Papers no. 153) (Urbana: Univ. Of Illinois, Graduate School of Library and Information Science, 1982), 6-10; Jane F. Spivack, "Finding a Job," in Jane F. Spivack, Careers in Information (White Plains, N. Y.: Knowledge Industry Publications, 1982), 183-197; Thomas Gaughan, "Resume Essentials for the Academic Librarian," College E Research Libraries 41 (Mar. 1980): 122-127.

2. Howze, "10 Job Hunting Tips for New Librarians," 490-491; Kay Womack, "Applying for Professional Positions in Academic Libraries: Meeting Minimum Requirements," Journal of Academic Librarianship 23 (May 1997): 205-209; MacAdam, "Job Hunter's Workshop," 357-361; Larsen and McConkey, "Applying for Professional Positions," 415-417; Broadway, "Job Descriptions visà-vis Applications," 197-200; Goldberg and Womack, "Academic Applicants," 701-705; Terrence Mech, "Recruitment and Selection of College Librarians," in Gerard B. McCabe, Operations Handbook for the Small Academic Library (Westport, Conn.: Greenwood Pr., 1989), 72-75; Billy R. 
Wilkinson, "Recruitment and Selection," in Sheila Creth and Frederick Duda, Personnel Administration in Libraries 2d ed. (New York: Neal-Schuman Publishers, 1989), 109; Wong, "Job Search," 40-41; Dewey, "Writing and Analyzing Resumes and Cover Letters," 62-79; Delzell, Finding a Position, 6-11; Spivack, "Finding a Job," 182-197; James M. Hillard, "Advice from an Employer to Applicants," American Libraries 12 (October 1981): 359.

3. Womack and Goldberg, "Resume Content," 540.

4. Ibid., 540-549.

5. Ibid., 541-545. Womack and Goldberg provide a more detailed description of the complete methodology and the results of part one of the survey in their earlier publication.

6. Ibid., 542-543. Womack and Goldberg describe in more detail the questions asked and the responses which were used to arrive at this conclusion.

7. Spivack, "Finding a Job," 184; Dewey "Writing and Analyzing Resumes and Cover Letters," 63.

8. MacAdam, "Job Hunter's Workshop," 359; Wong, "Job Search," 41; Delzell, Finding a Position, 6 .

9. Womack, "Applying for Professional Positions in Academic Libraries," 208.

10. Womack, "Applying for Professional Positions in Academic Libraries," 205-209; Janet Swan Hill (October 12, 1993), "Ignoring Qualifications," Libraries Administration and Management Discussion List [Online]. Available e-mail: libad@umab.bitnet; Mech, "Recruitment and Selection of College Librarians," 68; Dewey, "Writing and Analyzing Resumes and Cover Letters," 73.

11. MacAdam, "Job Hunter's Workshop," 358; Larsen and McConkey,"Applying for Professional Positions," 415; Stuart Hannabus, "Job Search-1," New Library World 83 (June 1982): 75.

12. Mech, "Recruitment and Selection of College Librarians," 68.

13. Larsen and McConkey, "Applying for Professional Positions," 415.

14. Womack, "Applying for Professional Positions in Academic Libraries," 209.

15. Mech, "Recruitment and Selection of College Librarians," 69.

16. Broadway, "Job Descriptions vis-à-vis Applications," 198; Mech, "Recruitment and Selection of College Librarians," 70.

17. Goldberg and Womack, "Academic Applicants," 702.

18. Broadway, "Job Descriptions vis-à-vis Applications," 197-198; Dewey, "Writing and Analyzing Resumes and Cover Letters," 60.

19. Broadway, "Job Descriptions vis-à-vis Applications," 198-199.

20. Goldberg and Womack, "Academic Applicants," 704.

21. Delzell, Finding a Position, 9; Hannabus, "Job Search-1," 75.

22. Barbara I. Dewey, "The Job Offer," in Barbara I. Dewey, Library Jobs: How to Fill Them, How to Find Them (Phoenix, Ariz: Oryx Pr., 1987), 109.

23. Elizabeth A. Lorenzen, "Librarian for Hire: Internet Surfing for Job Search Success," Technicalities 15 (Jan. 1995): 11-14; Delzell, Finding a Position, 5-6; Spivack, "Finding a Job," 174-175.

24. Lorenzen, "Librarian for Hire," 11-14.

25. Douglas G. Birdsall, "Recruiting Academic Librarians: How to Find and Hire the Best Candidates," Journal of Academic Librarianship, 17 (Nov. 1991): 278-279; Mech, "Recruitment and Selection," 67-68; Wilkinson, "Recruitment and Selection of College Librarians," 106-107; Barbara I. Dewey, "Legal Requirements and Job Advertising," in Barbara I. Dewey, Library Jobs: How to Fill Them, How to Find Them (Phoenix, Ariz: Oryx Pr., 1987), 49-57.

26. Womack and Goldberg, "Resume Content," 545, 547. 